\title{
A METHOD FOR VIRTUAL ANASTYLOSIS: THE CASE OF THE ARCH OF TITUS AT THE CIRCUS MAXIMUS IN ROME
}

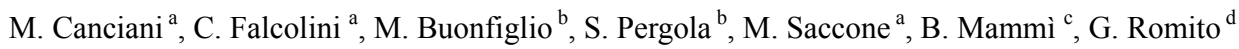 \\ ${ }^{a}$ Dipartimento di Architettura, Università degli Studi RomaTre - (marco.canciani, corrado.falcolini, mauro.saccone) @uniroma3.it \\ b Sovrintendenza Capitolina ai Beni Culturali di Roma Capitale - (marialetizia.buonfiglio, stefania.pergola)@comune.roma.it \\ ${ }^{\mathrm{c}}$ mammibruno@gmail.com \\ d romito.giorgia@gmail.com
}

KEY WORDS: Range based survey, Image based survey, 3D modelling, Archaeology, Virtual Anastylosis.

\begin{abstract}
:
This paper is the first report about the development of a methodology for the virtual Anastylosis of elements belonging to an archaeological site, based on the 3d modeling of fragments. This research is the result of the cooperation between Università Roma Tre, Dipartimento di Architettura and Sovrintendenza Capitolina ai Beni Culturali; several 3D survey, modeling, information systems and archaeology experts were involved. The purpose of the research was to study the complex and stratified site of the Arch of Titus at the Circus Maximus aiming, first of all, at completing the existing traditional graphic documentation using cataloguing and survey innovative methodologies, and, secondly, at supporting new proposals for the reconstruction and Anastylosis of the Arch itself. This tested methodology whose fundamental element is the three-dimensional textured model of each fragment, can also be used in other sites and contexts.
\end{abstract}

\section{INTRODUCTION}

The reconstruction of ancient monuments, that is to be more precise the reassembly of a site according to the layout and form in a given historical epoch, was a very common practice in the archaeological field during the $19^{\text {th }}$ and $20^{\text {th }}$ centuries. There are many references and examples about it (Brandi, C., 1991; Filetici, M. G., 1997; Marconi, P., 1984 ).

The introduction, recently, of modern information technology and survey instruments, has given a boost to the reconstructions of archaeological sites, above all thanks to the possibility of obtaining more and more accurate measurements, of organizing information in a better way, through the use of digital information systems and structured database and of reconstructing the monument as it was according to its original state in a virtual 3D environment, editable and upgradeable at any time. This process, called virtual Anastylosis, (Reilly, P., 1990), using range based and image based modeling digital techniques, makes a 3D model which reproduces a hypothetical copy of the original model, assembling surveyed fragments, present in the excavation site, with elements philologically reconstructed on the basis of historical knowledge and documentation. See, for example, De Luca, L., et al, 2011 and Kontogianni, G., et al., 2013. In order to obtain that, it is necessary to acquire for each single fragment, besides the textured three-dimensional model, which is the fundamental support, also some specific information for Anastylosis such as: orientation in the original position, contiguity or similarity to other fragments, belonging to a specific structure or element of the monument, characteristic section of mouldings, contact surfaces, trace of connection elements etc.

Our research aims at providing archaeologists with an operative instrument to support activities of indexing and documentation of fragments present in the excavation site, based on a system which links spatial information, given by three-dimension models, to descriptive information, useful for documentation and virtual Anastylosis procedures.

\subsection{Related works}

The process of virtual reconstruction is part of a broader field of study: the "Virtual Archaeology". Born in the '90s with Paul Reilly, which defines its main features (Reilly, P., 1990; Reilly, P., 1992), virtual archeology allows both to document and to check all stages of the excavation, through three-dimensional models and hypertext.

The 3D modeling enters into a relationship with archeology and, in a few years, its scope extends to the reconstruction of past environments, including buildings, landscapes and artefacts.

Ten years later Reilly's study, the definition of Forte «... virtual archeology can be defined as digital reconstructive archeology, computational epistemology applied to the reconstruction of three-dimensional archaeological ecosystems, therefore, cognitive ecology »(Forte, M., 2000), shows how important and widespread is the $3 \mathrm{D}$ modeling in this area.

To choose typology, forms and organization of data we have looked at the study of Sanctuary of Hera Lacinia in Crotone (Mezzetti, C., 2009) and in order to decide how to catch this data we have used integrated procedures for 3D Survey (Remondino, F., 2011). Our work is based on a study of architectural orders (Migliari, R., 1991) applied to virtual reconstruction. We have used our previous work (Canciani, M., et al., 2011) to study the relationship between theoretical and survey model and to support the process of virtual repositioning of fragments in their original location we.

To define the connection rules for virtual Anastylosis we look at two important studies, the first one (Li, D., et al., 2005) define the way to create a hierarchical model. The second one show some rules and features (like molders or clumping holes) very close to ours rules (Thuswaldner et al., 2009). Finally the aim of this work is the use of tridimensional object (obtained with survey) in a hierarchical /semantical way (De Luca 2011) but, in our interpretation, rules are defined by position, dimension and special features. 


\section{CASE STUDY: THE ARCH OF TITUS AT CIRCUS MAXIMUS IN ROME}

The method of cataloguing and virtual reconstruction of archaeological sites that we propose in this paper was adopted in the study carried out by the Laboratorio di Rappresentazione Grafica, dedicated to the 3D survey, and belonging to the Department of Architecture of the University Roma Tre, in collaboration with the Sovrintendenza Capitolina ai Beni Culturali di Roma Capitale, about the Arch of Titus at the Circus Maximus (see Figure 1) during a Master's degree in Restauro architettonico e recupero della bellezza dei centri storici. The collaboration between archaeologists and architects has allowed us not only to develop a project of reconstruction of the monument, but also a tool for study and detailed analysis that takes into account the specific needs of an archaeologichal excavation.

The Sovrintendenza Capitolina has been pursuing a challenging project which aims at the environmental restoration of the archaeological area of the Circus Maximus in Rome for several years. The circus, 600 meters long and about 150 wide, was the greatest monument of antiquity. The visible ruins refer to the reconstruction in brick and tufa begun by Domitian and triumphantly inaugurated in $103 \mathrm{AD}$ by Trajan.

The subject of research is the hemicycle area, in the centre of which was erected the majestic Arch of Titus, dedicated to the emperor Titus in $81 \mathrm{AD}$, the year of his death, to celebrate the triumph against the Jews and the destruction of Jerusalem (De Maria, S., 1988; Brandizzi Vitucci, P., 1990; Ciancio Rossetto, P., 1987; Ciancio Rossetto, P., 1993). It is possible to reconstruct its original appearance on the basis of ancient documents such as the Forma Urbis, some coins, sarcophagi and mosaics.

The Arch had three intercommunicating fornices, the central one was used for the triumphal processions in the imperial age (La Rocca, E., 2008). It was decorated with reliefs (Parisi Presicce, C., 2008) and with a great dedicatory inscription (CIL VI, 944), which is currently missing but its text remains, and it culminated on the attic with a bronze quadriga. Nowadays only a few fragments remain in situ: some composite style bases on the pedestals of columns and of pilasters of the front, some fragments of ribbed columns and other fragments of cornices of the crowning and of the attic. The Arch was probably still standing in the eighth century, later it suffered the same fate of many ancient monuments, having been stripped of the stone (travertine and marble), often reused in other buildings. In the Middle Ages, the course of the Acqua Mariana, an outdoor aqueduct created in 1122 by Pope Callistus II, was installed in the area along the Arch, to supply vegetable gardens and water mills. It transformed the appearance and function of the original building.

It is therefore a complex area hard to interpret, due to the presence of many structural overlaps.

In the case of virtual reconstruction were analyzed 27 fragments present in the site and belonging to the monument.

These fragments were examined considering their size in comparison with unity of measurement used in the ancient world, their condition and their position in relation to the dynamics of the collapse. The ability to recognize the possible points of contact between the various elements and the verification of the binding area of a block to another through the analysis of the specific techniques, has enabled us to locate the exact position fragments can begin to define in a scientific manner and specify the original appearance of the monument and its size, restoring a previously unpublished arc. The bases of the front columns still in situ make it possible to calculate the amplitude of the Arch; the reconstruction of the original appearance of its constituent parts is harder. Therefore as far as this project is concerned it is very useful to recognize any possible points of contact or overlap of the conserved elements, in function of future reconstruction hypothesis. This work has margins for improvement as the overall framework of reconstruction is going to be object of further elaboration in the coming months. As a matter of fact the cataloguing and contextualization of all stone fragments in the area will be completed and archaeological excavations in progress might bring to light other important architectural elements. For the purposes of virtual reconstruction of the monument, a survey data form, containing some basic information for the study of the individual elements, accompanied by a making up of the fragment with the 3D model, was developed.

In this survey data form, the definitions concerning examined pieces and suitable for a proposal of virtual Anastylosis, were chosen considering the voices of common terminology lists adopted by the Sovrintendenza Capitolina ai Beni Culturali and by other Authorities (Boldrighini, F., et al., 2007).

\section{THE PROCEDURE PIPELINE}

The procedure we adopt for the virtual reconstruction of an archaeological monument, such as the Arch of Titus, is developed following a sequence of operations concerning: a first phase of site survey, both general and specific, a second phase of collection, cataloguing and systematization of data, and a third phase of virtual Anastylosis concerning the planimetric, altimetric and three-dimensional configuration.

This work, was, specifically, carried out following a pipeline divided into nine different procedures:

1) 3d survey: concerning the whole excavation site and done through laser scans. A reference and georeferencing system and the dimensioning of every single fragment are determined through it.

2) Point cloud segmentation: identification and naming of the single fragments, dividing the point cloud into as many portions.

3) Data acquisition: collection of historical documentation and specific survey, carried out through image based modeling, of each fragment; detection of fragments still in situ.

4) $3 D$ model rendering: making of textured three-dimensional models, oriented on the basis of the original position (horizontation and verticality), and proportioned according to the scale concerning the corresponding portions of the point cloud, verification of reconstruction in conjunction with Archaeologists.

5) Data organization: indexing of every single fragment with textured and scale $3 \mathrm{~d}$ model, extraction of measures useful to the comparison with other fragments and of characteristics (horizontal and vertical sections, detail sections of mouldings, using methodologies applied in Canciani, M., et al, 2013, traces of Anatyrosis and link bolts). Defining the database and possible connection with further information bases.

6) Virtual Anastylosis of the planimetry: reconstruction of the original plane, on the basis of in situ elements, and comparison of historical documentation (Vitruvio libro III, 3,10 -13 e libro IV, 1,$7 ; 11$ );

7) Anastylosis in elevation: reconstruction of the development of the order in elevation of a column, on the basis of historical documentation, proportioning reported in manuals or documents (Migliari, R., 1991) and comparison with similar or contemporary monuments.

8) 3D virtual Anastylosis: concerning the entire complex of the Arch of Titus, on the basis of the integration between the planimetric and the altimetric reconstruction. 
9) Information system: connection between the model, structured according to fragments placed back into their original position, and survey data forms related to them.

\subsection{Case study for documentation and Anastylosis: The Arch of Titus}

In the archaeological area of the Circus Maximus, concerned by our study, the 27 findings, some of which are still in situ, presumably attributable to the Arch of Titus, are consisting of column drums, portions of the basement, rests of one of the pylons and other stone blocks of regular shape.

Our work looked forward in making a new general planimetry and the documentation of the Sovrintendenza capitolina for the excavate of the arch of Tito, but also regarding the method for the virtual anastylosis.

To do this we developed different survey form, one for each fragment, useful to get a features and characteristics: dimensional, constructive and techniques.

Using a rigorous method, we gathered very important information that let us make these tables. One for each fragment, where we put all the data of each artefact.

For example in the fragment of "column drums" F03 (Figure.2); the survey form include:

1) Denomination of the fragment and reference photograph.

2) Description of the fragment according to the words of the common terminology lists adopted by Sovrintendenza Capitolina ai Beni Culturali (Boldrighini, F., et al., edited by, 2007), with the possible connection to database used by other institution.

3) Finding the geometric axis, where the fragment is defined by a cylinder.

4) Planimetric excerpt with framework of the fragment.

5) Axonometric view where the orientation of the fragment is defined and compared to its original position. This is traced through the creation of a cylindrical envelopment of the piece and the indication of its vertical axis.

6) Top and front view of the textured tridimensional model.

7) Extraction of dimensional features:

- horizontal sections useful to the indication of the $n$ dimensional measurements, arranged in sequence according to the blocks taper;

- vertical sections with the indication of measurements

8) The zoom of a horizontal section and the reconstruction of the geometric model of a column with the fluting.

9) Presence of technical features, useful for the anastylosis: - anathyrosis;

- presence of pivoting;

- presence of connection holes for clamps and for lifting;

Referring at the extraction of the moldings realized with the method illustrated on paragraph 3.2 (Canciani, M., 2012),

identifying the presence of pivoting, anathyrosis and contact surfaces.

The survey process used was done integrating threedimensional data coming from different systems:

- Range-based process for the acquisition and modelling of the data with a laser scanner that allows to have directly the point in the space of the surface or of the point surveyed. It also obtains directly and in not a lot of time big quantities of data about a complex geometry. This method has been used for georeferencing of the entire excavation.

- Image based: based on metric elaboration of images, that have all the necessary information to reproduce the geometry and the texture of the object. Photographed and generated three-dimensional models. This method has been used for the modeling of individual fragments

This type of three-dimensional data, that comes from the above processes, can be easily updated with other metric information coming from reliefs that can be direct and maps. To have a correct georeferencing and a model in scale.

We can put the use of these instruments inside a well known process codified, in wich particular attention has to be put specially in the phase of integration between traditional and innovative methods.

All of this data were organized in a general database which allowed the creation of an informative system able to interpolate all data and to identify two or more contiguous fragments.

During the different steps of the work, carried out in October 2012, there was also a focus on the planimetric updating; for this reason it was made a first comparison between the previous plan and the cloud of points obtained by the survey made through the scanner laser (Leica HDS 6000). Then it emerged that some findings were no longer present in the site, because they had been moved or buried along the years, or they hadn't been reported in the plan we had.

The discovery of new fragments belonging to the Triumphal Arch entailed a further updating, carried out through the use of $123 \mathrm{~d}$ Catch software, which gave, as a result, a textured mesh of the area, compared, graduated and oriented according to the point cloud, through the use of Leica Cyclone and Technodigit 3D Reshaper software.

\subsection{Algorithms for virtual Anastylosis}

Information about fragment features allow analysis at different levels of accuracy. In order to fix the position of a rigid body in space (having fixed a reference orthogonal system of coordinates $(\mathrm{X}, \mathrm{Y}, \mathrm{Z})$ with origin in $\mathrm{O})$ in general 6 free parameters (degrees of freedom) are needed: 3 coordinates $(\mathrm{x}$, $\mathrm{y}, \mathrm{z})$ for the position of one point and 3 angles (Euler's angles) for its orientation $(\theta, \varphi, \psi)$.

The position in situ of the bases of two columns of the Arch of Titus fix the orientation of the hypothesized model and its position in space: all degrees of freedom of these elements are then determined univocally and we choose to take the reference system with axis parallel to the principal directions of the structure.

For the largest fragments the number of degrees of freedom has been sensibly reduced by giving a relative orientation which allows them to be placed as a function of one or two parameters, having fixed the others using a virtual model of the Arch based on historical documentation and compatibility with architectonical elements.

Fragment features, as stated, include horizontal and vertical sections and the relative position of some special points, like the center of connection holes and the intersection points of the rotation axis with the drum or the column base (see Figure 3).

For example a drum, vertically oriented, is placed on one of the 8 columns of the virtual model leaving its own up/down direction and vertical position free: using the featured horizontal sections it is then possible to automatically fix its altitude and direction, if there is an evident taper, or an interval in the variable $\mathrm{z}$ if it seems more probable to place the fragment in the first third (not tapered) of the column.

In absolute coordinates this means storing the position of such a fragment as a string $\left(\mathrm{x}_{0}, \mathrm{y}_{0},\left[\mathrm{z}_{1}, \mathrm{z}_{2}\right], \theta, \varphi_{0}, \psi_{0}\right)$ where $\mathrm{x}_{0}, \mathrm{y}_{0}$ are the position of one of the columns, $\left(\varphi_{0}, \psi_{0}\right)$ the orientation of the Arch base plane, while $\theta=\theta_{0}+2 \mathrm{k} \pi / 24$ (k integer) gives the possible rotated position of the flutings.

In any case, an analysis of contact probability of two fragments, using the recorded features and the measure of some morphological indicators, such as surface roughness, area and volume descriptors (see for example Thuswaldner, et al., 2009) of the possible contact surfaces, follows.

An example of morphological indicator is a volume descriptor centered on one of the recorded special points: let $\mathbf{p}$ be a point 
of a given fragment $\mathrm{F}, B_{r}(\mathbf{p})$ the sphere centered in $\mathbf{p}$ of radius $r$, and $V^{r}(\mathbf{p})$ the volume fraction of $B_{r}(\mathbf{p}) \cap F$. More precisely:

$$
V^{r}(\mathbf{p})=\frac{3}{4 \pi r^{3}} \int_{B_{r}(\mathbf{p})} \chi_{F} d \mathbf{x}
$$

were $\chi_{F}$ is the characteristic function of $F$. This indicator allows the matching probability of two drums to be automatically estimated, under the condition that $V^{r}(\mathbf{p})<1-V^{r}(\mathbf{q})$, for $\mathbf{p}$ and $\mathbf{q}$ belonging to different fragments and sharing the same position in space.

The estimated value of this indicator has been used to validate the correct placement of the first part of the column (piece F04) over a base in situ (piece F02).

A more accurate semi-automatic calculation is made on all fragments that exceed a given threshold of contact probability, which is also used to group together potentially adjacent fragments using a connection graph.

Fragments with entablature parts can be instead univocally placed in one of the linear developments of the virtual model, chosen by identifying the automatically computed section moulding (Canciani, M., et al., 2013) which gives also an explicit recording obtained by the ordered sequence of Arches and oriented segments. In absolute coordinates, a given entablature fragment is stored at the position $\left(\mathrm{x}_{0}, \mathrm{y}, \mathrm{z}_{0}, \theta_{0}, \varphi_{0}\right.$, $\left.\psi_{0}\right)$ or $\left(\mathrm{x}, \mathrm{y}_{0}, \mathrm{z}_{0}, \theta_{0}, \varphi_{0}, \psi_{0}\right)$ with the unique coordinate $\mathrm{x}$ (or $\left.\mathrm{y}\right)$ variable along the corresponding longitudinal or transversal direction of the Arch. Also in this case a more accurate analysis of elements of the same connection group of possibly adjacent fragments follows.

in the variable $\mathrm{z}$ if it seems more probable to place the fragment in the first third (not tapered) of the column. In absolute coordinates this means storing the position of such a fragment as a string $\left(\mathrm{x}_{0}, \mathrm{y}_{0},\left[\mathrm{z}_{1}, \mathrm{z}_{2}\right], \theta, \varphi_{0}, \psi_{0}\right)$ where $\mathrm{x}_{0}, \mathrm{y}_{0}$ are the position of one of the columns, $\left(\varphi_{0}, \psi_{0}\right)$ the orientation of the Arch base plane, while $\theta=\theta_{0}+2 \mathrm{k} \pi / 24$ ( $\mathrm{k}$ integer) gives the possible rotated position of the flutings.

In any case, an analysis of contact probability of two fragments, using the recorded features and the measure of some morphological indicators, such as surface roughness, area and volume descriptors (see for example Thuswaldner, et al., 2009) of the possible contact surfaces, follows.

An example of morphological indicator is a volume descriptor centered on one of the recorded special points: let $\mathbf{p}$ be a point of a given fragment $\mathrm{F}, B_{r}(\mathbf{p})$ the sphere centered in $\mathbf{p}$ of radius $r$, and $V^{r}(\mathbf{p})$ the volume fraction of $B_{r}(\mathbf{p}) \cap F$. More precisely:

$$
V^{r}(\mathbf{p})=\frac{3}{4 \pi r^{3}} \int_{B_{r}(\mathbf{p})} \chi_{F} d \mathbf{x}
$$

were $\chi_{F}$ is the characteristic function of $F$. This indicator allows the matching probability of two drums to be automatically estimated, under the condition that $V^{r}(\mathbf{p})<1-V^{r}(\mathbf{q})$, for $\mathbf{p}$ and $\mathbf{q}$ belonging to different fragments and $|\mathbf{p}-\mathbf{q}|<<1$.

A more accurate semi-automatic calculation is made on all fragments that exceed a given threshold of contact probability, which is also used to group together potentially adjacent fragments using a connection graph.

Fragments with entablature parts can be instead univocally placed in one of the linear developments of the virtual model, chosen by identifying the automatically computed section moulding (Canciani, M., et al., 2013) which gives also an explicit recording obtained by the ordered sequence of Arches and oriented segments. In absolute coordinates, a given entablature fragment is stored at the position $\left(\mathrm{x}_{0}, \mathrm{y}, \mathrm{z}_{0}, \theta_{0}, \varphi_{0}\right.$, $\left.\psi_{0}\right)$ or $\left(\mathrm{x}, \mathrm{y}_{0}, \mathrm{z}_{0}, \theta_{0}, \varphi_{0}, \psi_{0}\right)$ with the unique coordinate $\mathrm{x}$ (or $\left.\mathrm{y}\right)$ variable along the corresponding longitudinal or transversal direction of the Arch. Also in this case a more accurate analysis of elements of the same connection group of possibly adjacent fragments follows.

\section{CONCLUSION}

The method we experienced in ongoing investigations on the Arch of Titus has led to a number of results, both in regard to the issues of the method, both regarding the questions about the detected object.

Regarding the first point, the system has the undoubted advantage to organize the elements of the excavation in a database, containing all the data collected and connected to a catalog of three-dimensional objects, as previously described. The system also allows you to determine the key elements on which to develop, with a rigorous process, the various hypotheses of virtual reconstructions. This model is always editable, in case of changing the starting hypothesis, and upgradeable when, for example, is found a new fragment to replace.

Regarding the second point, the system that we have experienced in the excavation of the Arch of Titus, has produced a first hypothesis of virtual anastylosis on two of the eight columns that adorned the fronts of the Arch (Figure 4.), in which the fragments F01, F02, F12, F16, F26, F27, being elements in situ, or already placed in the original position, solve the six equations of freedom ( 3 coordinates and 3 rotations); 20 fragments, with specific characteristics that allow to block two or more parameters, are relocated on the basis of the position statistically more likely; the fragment F03 (Figure 5.), relative to a column drums, having identified the contact surface with the base F02 (in situ), the traces of the corresponding connection holes for clamps and alignments, solving all six equations of freedom, is relocated in virtual anastylosis in its exact original position. This fragment provides evidence of the utility of the method tested by us.

\section{REFERENCES}

Atenian Agora Excavations by the American School of Classical Studies of Athens http://agathe.gr//

Boldrighini, F., et al., edited by, 2007, Arcata, Archeologia e catalogazione, Roma.

Brandi, C., I restauri dell'agorầ di Atene, in Viaggio nella Grecia Antica, 1990

Brandizzi Vitucci, P., 1990. L'arco di Tito al Circo Massimo. In: Archeologia Laziale, Roma, Italy, Vol. X, pp. 68-71.

Canciani, M., Saccone, M., 2011. The Use Of 3d Models In Integrate Survey: The Church Of St. Thomas Of Villanova In Castel Gandolfo, Int. Arch. Photogramm. Remote Sens. Spatial Inf. Sci., Vol. XXXVIII-5/W16, pp. 591-597.

Canciani, M., Falcolini, C., Saccone, M., Spadafora, G., 2013. From point cloud to Architectural models: algorithms for shape reconstruction. In: ISPRS Archives-Vol. XL-5/W1.

Carella, M., 2010. Rilievo e anastilosi virtuale della peristasi meridionale del tempio "G" di Sellinunte. Università degli Studi di Palermo, Tesi di laurea, relatore prof. Fabrizio Agnello.

Carra, G., D’Amelio, S., Villa, B., 2008. The Virtual Reconstruction Of Temple B In Selinunte Excavation Site. In: ISPRS Congress - Vol. XXXVII Part B5, pp. 391-396. 
Ciancio Rossetto, P., 1987. Circo Massimo. Il circo cesariano e l'arco di Tito. In: Archeologia Laziale, Roma, Italy, Vol. VIII, pp. 44-46.

Ciancio Rossetto, P., 1993. s.v. Arcus Titi . In: LTUR, Roma, Italy, Vol. I, pp. 108 ss.

\section{CIL, Corpus Inscriptionum Latinarum, Berolini 1862 ss.}

De Luca, L., Busayarat, C., Stefani, C., Véron, P. \& Florenzano, M. (2011) A semantic-based platform for the digital analysis of architectural heritage. Computers \& Graphics, 35, 227-241.

De Maria, S., 1988. Gli Archi Onorari di Roma e dell'Italia romana, Roma, Italy, pp. 119, 285-287, n. 73.

Filetici, M., G., 'Il frammento nel restauro archeologico, L'integrazione di alcuni capitelli del Tempio Rotondo al Foro Boario, in ' $L a$ reintegrazione nel restauro dell'antico. La protezione del patrimonio dal rischio sismico, a cura di M.M. Segarra Lagunes Roma 1997

Forte, M., 2000. About virtual Archaeology: disorders, cognitive interactions and virtuality. In: Virtual Reality in Archaeology, pp. 247-259.

Kontogianni, G., Georgopoulos, A., Saraga, N., Alexandraki, E., and Tsogka, K., 2013. 3D Virtual Reconstruction Of The Middle Stoa In The Athens Ancient Agora, Int. Arch. Photogramm. Remote Sens. Spatial Inf. Sci., Vol. XL-5/W1, pp. 125-131.

Kurdy, M., Biscop, J-L., De Luca, L., 2011. 3d virtual Anastylosis and reconstruction of several buildings in the site of saint-simeon, Syria. In: XXII ISPRS Congress, Trento, Italy, Vol. XXXVIII-5/W16.

La Rocca, E., 2008. La processione trionfale come spettacolo per il popolo romano. Trionfi antichi, spettacoli moderni. In: Trionfi Romani (Catalogo della Mostra), Roma, Italy, pp. 3455 .

Li, D., Hong, T., Zhu, Y., Yang, J., 2005. 3D Reconstruction and simulating assembly of ancient chinese timber-structure building. In: The proceedings of CIPA 2005 XX International Sympsium, Torino, Italy, pp. 906-911.

Marconi, P., Arte e cultura della manutenzione dei monumenti, Bari 1984

Mezzetti, C., 2009. Il santuario di Hera al Capo Lacinio : l'analisi della forma, il restauro, la ricerca Archeologica. Kappa, Roma.

Migliari, R., 1991. Il disegno degli ordini e il rilievo dell'Architettura classica: Cinque pezzi facili. In: Disegnare, 2, Roma, pp. 49-66.

Parisi Presicce, C., 2008, L'Arco di Tito al Circo Massimo. In: Le due patrie acquisite. Studi di archeologia dedicati a Walter Trillmich. BCom. Suppl. Vol. 18, Roma, Italy, pp. 345-354.

Reilly, P., 1990. Towards a virtual Archaeology. In: Computer Applications and Quantitative Methods in Archaeology 1990. Oxford: British Archaeological Reports (Int. Series 565), pp. 312-322.

Reilly, P., 1992. Three-Dimensional modelling and primary Archaeological data. In: Archaeology and the Information Age, London: Routledge, 147-173

Remondino, F., 2011. Rilievo e modellazione 3D di siti e Architetture complesse. In: Disegnare con, Vol. 4(8), pp. 90-98.

Remondino, F., 2011b. A web-based interactive tool for multiresolution 3d models of a Maya Archaeological site, Int. Arch. Photogramm. Remote Sens. Spatial. Inf. Sci., Trento, Italy, Vol. XXXVIII-5/W16, 201.

Scagliarini, D., Guidazzoli A., Salmon, T., et al., 2003. Archeologia virtuale e supporti informatici nella ricostruzione di una domus di Pompei, In: Archeologia e Calcolatori, 14, pp. 237-274.

Thuswaldner, B., Flory, S., Kallasek, R., Hofer, M., 2009. Digital Anastylosis Of The Octagon In Ephesos. In: Journal on Computing and Cultural Heritage, 2,1 pp. 1-27

Vitruvius M.P., De Architectura

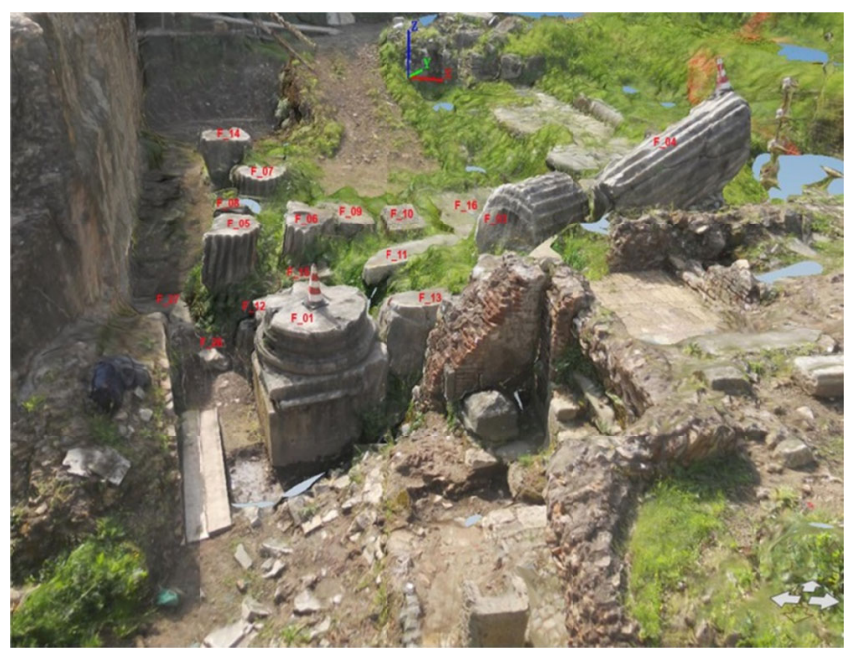

Figure 1. Circus Maximus in Rome: model reconstructed through the process of image-based modeling.
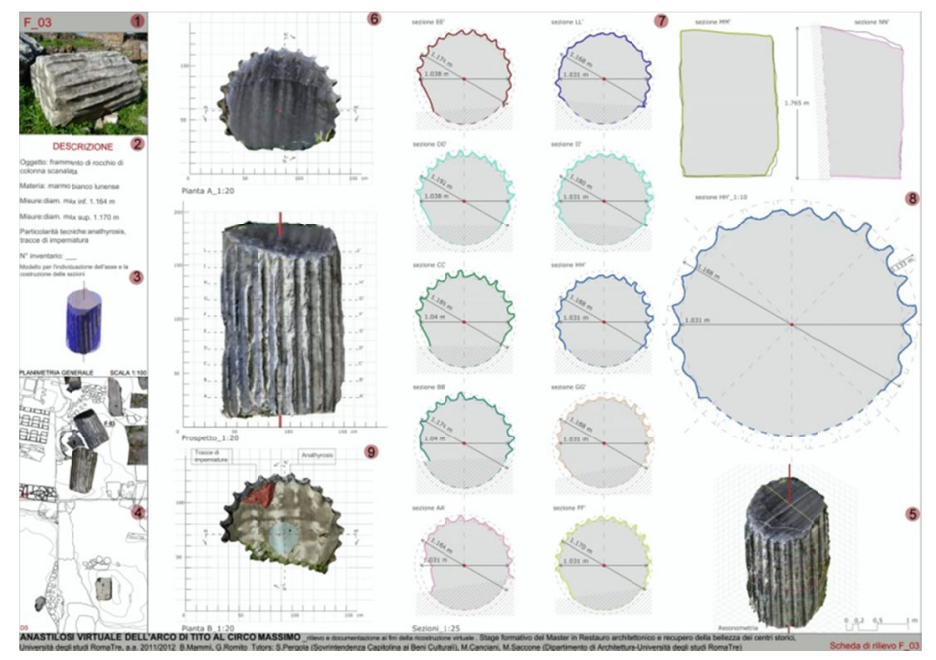

Figure 2. Remains of the Arch of Titus. Survey data form related to fragment F03 on column drum 


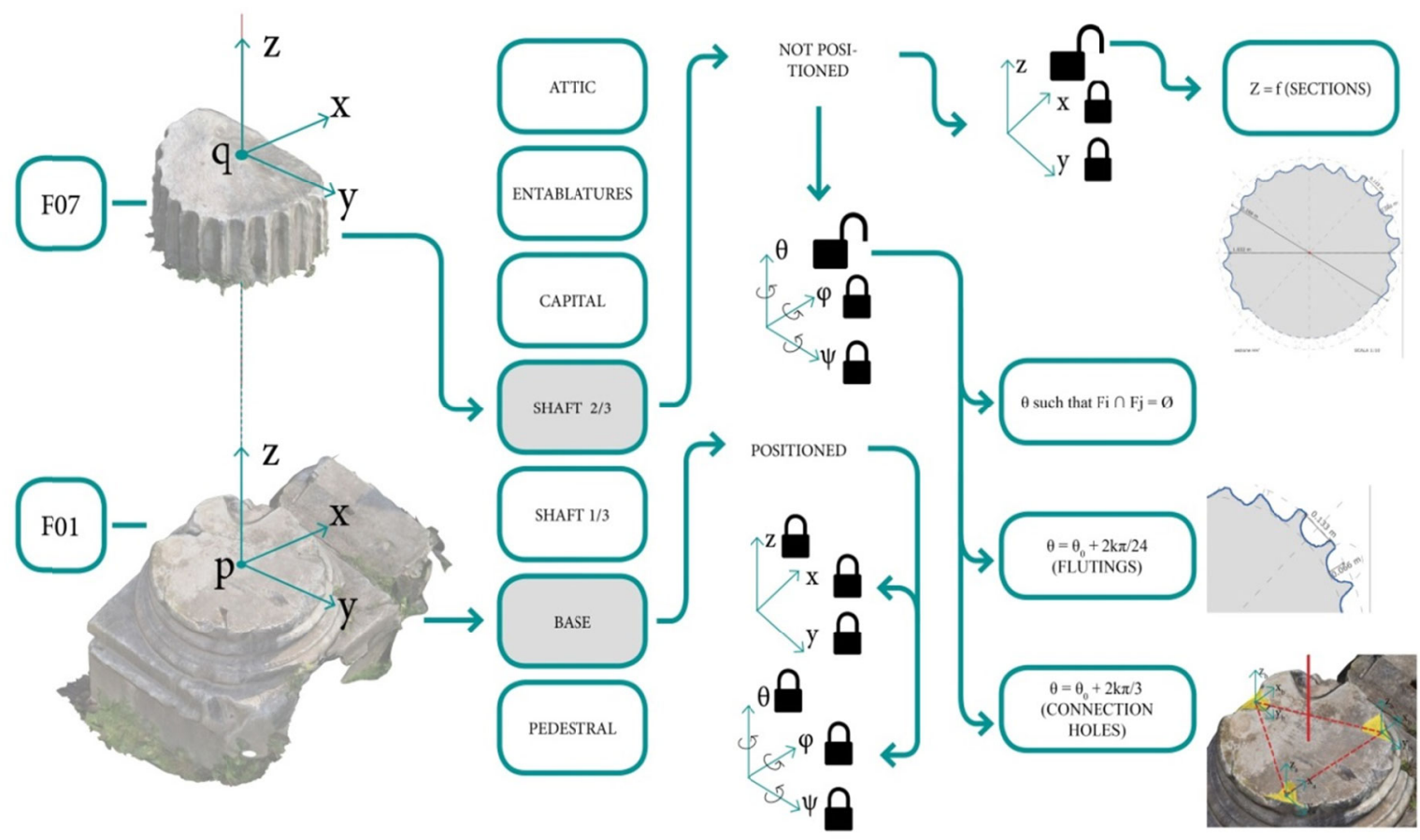

Figure 3. Remains of the Arch of Titus. Scheme with the six degrees of freedom of the fragments F01 and F07, and the possible links, useful for Virtual anastylosis.
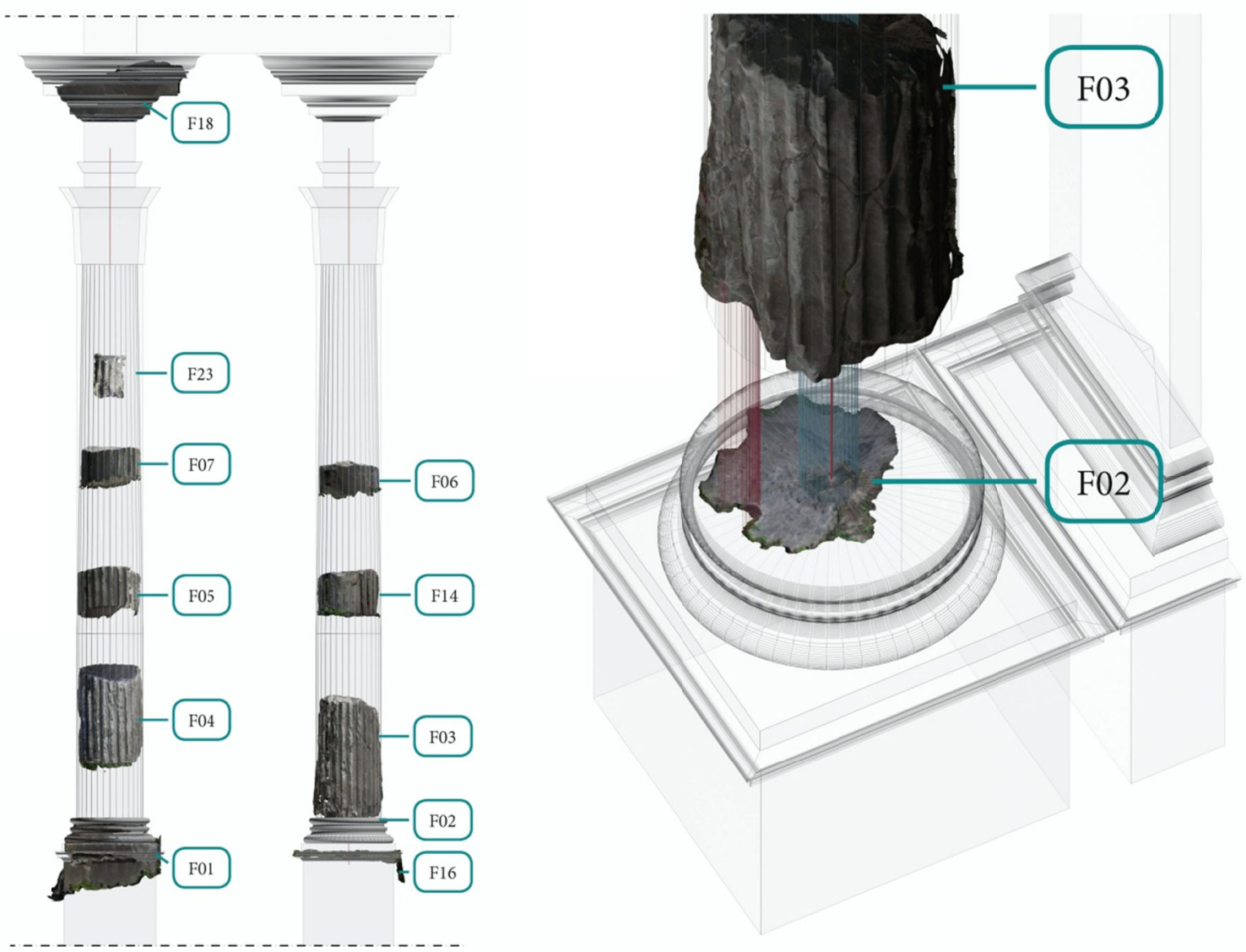

Figures 4 and 5. Virtual Anastylosis of the Arch of Titus. Repositioning of the fragments found in the excavation site in a hypothetical three-dimensional model of the original shape of the Arch: the front view of two columms on the left lateral fornix and detail of exploded axonometric view of the right column base (F02) and the nearest column drum (F03). 